\title{
Role of Perceptual and Non Perceptual Properties in 5 Year-Old's Categorization: Instructions Based on Objects or on Objects Properties
}

\section{F. Bonthoux and C. Berger}

\author{
(2) OpenEdition \\ Journals \\ Electronic version \\ URL: http://journals.openedition.org/cpl/197 \\ DOI: $10.4000 / \mathrm{cpl} .197$ \\ ISSN: $1379-6100$ \\ Publisher \\ Centre PsyCLÉ
}

Printed version

Date of publication: 1 December 2001

Electronic reference

F. Bonthoux and C. Berger, « Role of Perceptual and Non Perceptual Properties in 5 Year-Old's

Categorization: Instructions Based on Objects or on Objects Properties », Current psychology letters

[Online], 2001/3, 6 | 2001, Online since 05 September 2003, connection on 08 September 2020. URL

http://journals.openedition.org/cpl/197 ; DOI : https://doi.org/10.4000/cpl.197

This text was automatically generated on 8 September 2020 .

(c) All rights reserved 
Role of Perceptual and Non Perceptual Properties in 5 YearOld's Categorization: Instructions Based on Objects or on Objects Properties

F. Bonthoux and C. Berger 